\title{
Evaluation of risk of premalignant and malignant changes of the cervix in systemic lupus erythromatosis patients
}

Nagy M. Metwally Ahmed

Obstetrics and Gynecology Department, Faculty of Medicine; Zagazig University. Zagazig, Egypt

Corresponding author: Nagy M. Metwally Ahmed, Lecturer of Obstetrics and Gynecology, Obstetrics and Gynecology Department, Faculty of Medicine; Zagazig University. Zagazig, Egypt.

Received date: December 16, 2019; Accepted date: January 02, 2020; Published date: January 07, 2020

Citation: Metwally Ahmed NM. (2020) Evaluation of risk of premalignant and malignant changes of the cervix in systemic lupus erythromatosis patients. J Women Health Care Issues, 3(1); Doi/10.31579/2642-9756/017

Copyright: (C) 2020 Nagy M. Metwally Ahmed, This is an open access article distributed under the Creative Commons Attribution License, which permits unrestricted use, distribution, and reproduction in any medium, provided the original work is properly cited.

\begin{abstract}
:
Introduction: Cervical cancer is the second most common malignancy among women all over the world and a leading cause of death in females. There are known risk factors in this regard including immunosuppression condition like SLE. Screening of women could decrease the incidence of cervical cancer dramatically by detection of early premalignant changes in the tissue. There was significant debate as female with SLE did in fact have an increased risk of cancer compared to the general population. Our study was conducted to determine the prevalence of abnormal cervical smear and colposcopy finding in patients with SLE.

Patients and Methods: Our study was carried out on 128 participants (64 SLE patients and 64 apparently healthy individuals as a control group). Patients were recruited from Rheumatology, Obstetrics and Gynecology Department of Armed Forces Hospitals of South Region. Gazan, KSA. The study was explained to all patients and informed consent was obtained before enrollment in the study. All patients underwent thorough complete history taking, clinical evaluation, local and bimanual examination, speculum examination with pap smear intake, colposcopy examination to whom have abnormal pap smear patients with suspicious area, multiple biopsies where be taken for histopathology examination.

Results: The results of our study demonstrated that, there is a significant association between cervical cancer and SLE patients $(\mathrm{p}=0.034)$. There is a significant association between ASCUS (Atypical squamous cells of undetermined significance) with younger age of marriage $(\mathrm{p}=0.019)$ and shorter duration of SLE $(0.014)$. There is a significant association between cervical cancer with coital bleeding and history of cervical lesion $(\mathrm{p}=0.003)$. There is a high significant association between cervical cancer (especially ASCUS and CIN II) with passive smoking. Other examined parameters did not show any significant association $(\mathrm{p}>0.05)$.

Key Words: Premalignancy; Malignant Changes; cervix
\end{abstract}

\section{Introduction}

Although the overall mortality of patients with carcinoma of the cervix has decreased over the years on account of the widespread availability of effective screening programs, cervical cancer is the second most common malignancy in women and a major cause of morbidity and mortality, It an approximately represented by 510,000 newly diagnosed cases and 288,000 related deaths. Overall, the 5-year survival rate has been reported to be $73 \%$, but the prognosis unsatisfactory [1].

Cervical cancer was recognized for decades to behave as a sexually transmitted disease, Sexually transmitted HPV infection was implicated in its pathogenesis. In the mid-1970s, Meisels and Fortin recognized, on morphologic grounds, that HPV infection of the cervix occurred frequently, often with the histological characteristics of mild CIN [2].

Systemic lupus erythematosus (SLE), or lupus, is a chronic, progressive, autoimmune disorder that affects multiple organ systems, with a broad range of clinical and laboratory manifestations. The term lupus means wolf in Latin and is named as such because of facial lesions found in the disease process that are reminiscent of a wolf 's bite [3].

An important complication of SLE is increased incidence of malignancy including cervical cancers, autoimmune system dysfunction, recurrent infections. The immunosuppressive medication exposure may constitute explanations which suggest increased incidence of malignancy in SLE [4].

Cytology has been applied to the diagnosis of HPV infections of the penis, vulva, anus, and cervix through (Pap smear). The Papanicolaou-stained (Pap) smear is the most common method for detecting high-risk HPV. This method was named after pathologist George Papanicolaou, who pioneered this method in 1949, before HPV was implicated in cervical cancer. It is a screening tool for morphological changes in cervical cells [5].

Determined the occurrence of cervical dysplasia and Pap smear abnormalities in patients with systemic lupus erythematosus. The demonstrated that patients with SLE have more risk of cervical dysplasia than general population; they suggested that epidemiological surveillance of this group of patients should be more careful, with pap smear more early in life and probably every 6 months apart [6].

Studied the prevalence of abnormal cervicovaginal smears in patients with systemic lupus erythematosus. They concluded that cervicovaginal smearing is an easy, economic, safe, repeatable and noninvasive technique for screening and early detection of cervical neoplastic lesions in SLE [7].

Aim of the work: 
The aim of this study is to determine the relationship between systemic lupus erythematosus and premalignant and malignant changes of cervix

Subjects and methods:

\section{The subjects;}

A cross sectional case control study was conducted on 128 include 64 SLE patients. The ages of collected cases ranged from 22 to 43 years (mean \pm SD31.5 \pm 6.2 years). The disease duration ranged from 1.5 to 16 years (mean \pm SD11.1 \pm 4.9 years). In addition to this study include 64 healthy volunteers not known to suffer from any rheumatological manifestations as control group. All cases were collected during the period (from June 2017 to February 2019)

These patients were collected from Rheumatology, gynecology and obstetrics department, Armed Forces Hospitals of South Region. Gazan KSA

\section{Inclusion criteria:}

- Sexually active female patients.

- Females not pregnant at the time of the Pap smear intake.

- Females consenting to be included in the study.

\section{Exclusion criteria:}

- Patients with bleeding.

- Pregnant ladies.

- Patients refusing examination or participation in the study.

- Virgin.

\section{Design of the studv;}

\section{All patients were subjected to the followings:}

- Complete history taking.

- General examination.

Both patients and control group were subjected to the following

- Local and bimanual examination.

- Speculum examination with Pap smear intake.
- Colposcopic examination to whom has abnormal pap smear, multiple biopsies where be taken form patient was suspicious area by Colposcope for histopathological examination.

Written informed consents were obtained from each patient participating in this study after informing them about the steps of study.

Each participant was subjected according to guidelines in 2013:

1. Patient is positioned on an exam table in lithotomy Position and a speculum is gently inserted to open the vagina. The speculum allows to view the cervix and upper vagina.

2. We examine the cervix and take pap smear by Ayer's spatula applied on ectocervix including TZ and roatated $360^{*}$ and acytobrush applied inside endocervical canal and rotated and collected ectocervical and endocervical smears rapidly spread over a glass slide and immediately fixed the smear in95\% ethyl alcohol

3. Colposcopic examination was done to cervix:

A. Firstly, wash cervix with saline technique and examination of abnormal blood vessel pattern (Punctuation-, Mosaicism-Sharply demarcated borders).

B. We apply $5 \%$ acetic acid with a cotton ball held in a ring forceps. This gently applies lots of vinegar quickly and without trauma. Repeat application every five minutes. To show acetowhite areas that have sharp geographic boarders and a dimension of thickness or roughness are likely to be histologically more sever and to detect depth of the lesion. The presence of vessel atypia in any lesion implies more severe dysplasia.

C. Lugol's iodine (Schiller's test) to show negative iodine area.

4. Multiple biopsies were taken from patient with suspicious areas by colposcope for histopathological examination were fixed in $10 \%$ buffered formalin and embedded in paraffine blok and cut at 3-4 microsection and stained with Hematoxylin and Eosin (H\&E) stain. [9]

5. Provide careful post-procedure instructions. Advise no douching, intercourse, or tampons until spotting subsides (or until return visit). Patients are instructed to return for foul vaginal odor or discharge, pelvic pain, or fever. Tylenol, ibuprofen, or Aleve may be used for cramps (if any). Otherwise, follow-up is usually in 1 to 3 weeks to discuss histopathology results.

\section{Statistical analysis}

Data entry and statistical analyses were performed using SPSS (statistical package of social sciences) version 21 (SPSS Inc., Chicago, IL, Categorical data were expressed in number and percentage. Continuous normally distributed data were expressed in mean and standard deviation (10). The quantitative data were examined by Kolmogrov Smirnov test for normality of data [11]. Statistical significance was considered when probability $(\mathrm{P})$ value was less than or equal to 0.05 .

Student $\mathrm{T}$ test was used for continuous normally distributed data. To study the association between categorical data in SLE patients with those of the control group using chi square test or fisher exact test. Comparison of continuous data with various types of cancer cervix was conducted ANOVA (analysis of variance). 
Results:

A case control study was conducted on 64 SLE female patients as well as 64 females' healthy volunteers were selected as control group. There was no statistically significant difference between SLE and control group regarding the Demographic characteristics. The results of our study demonstrated that, there is a significant association between cervical cancer and SLE patients $(p=0.034)$. There is a significant association between ASCUS with younger age of marriage $(\mathrm{p}=0.019)$ and shorter duration of SLE (0.014)
There is a significant association between cervical cancer with coital bleeding and history of cervical lesion $(\mathrm{p}=0.003)$. There is a high significant association between cervical cancer (especially ASCUS and CIN II) with passive smoking. Other examined parameters did not show any significant association $(\mathrm{p}>0.05)$.

In our study, we investigated the Performance values of Pap smear and colposcopy in comparison with histopathology results, pap smear had $60 \%$ sensitivity, $100 \%$ specificity, $100 \%$ positive predictive value, $93.1 \%$ negative predictive value. While colposcopy showed higher results $80 \%$ sensitivity, $100 \%$ specificity, $100 \%$ positive predictive value, $96.4 \%$ negative predictive valu

\begin{tabular}{|c|c|c|c|c|}
\hline & & $\begin{array}{c}\text { SLE } \\
N=64\end{array}$ & $\begin{array}{c}\text { Control } \\
\mathrm{N}=64\end{array}$ & $P$ value \\
\hline \multicolumn{2}{|l|}{ Age mean \pm SD } & $31.5 \pm 6.2$ & $34.5 \pm 7.5$ & 0.062 \\
\hline \multicolumn{2}{|l|}{$\begin{array}{l}\text { Age of marriage } \\
\text { mean } \pm \text { SD }\end{array}$} & $28.8 \pm 6.5$ & $29.1 \pm 7.7$ & 0.903 \\
\hline \multicolumn{2}{|c|}{$\begin{array}{l}\text { Duration of marriage } \\
\text { mean } \pm \text { SD }\end{array}$} & $7.8 \pm 3.2$ & $6.4 \pm 4.1$ & 0.821 \\
\hline \multicolumn{2}{|c|}{$\begin{array}{l}\text { Duration of SLE } \\
\text { mean } \pm \text { SD }\end{array}$} & $11.1 \pm 4.9$ & ---- & ---- \\
\hline \multirow{2}{*}{$\begin{array}{l}\text { Multiple marriage } \\
\text { No }(\%)\end{array}$} & Once & $28(87.5)$ & $29(90.6)$ & \multirow{2}{*}{0.691} \\
\hline & twice & $4(12.5)$ & $3(9.4)$ & \\
\hline
\end{tabular}

Table 1: Demographic characteristics of the study

\begin{tabular}{|c|c|c|c|c|}
\hline & & SLE N=64 & Contro $\mathrm{IN}=64$ & $P$ value \\
\hline \multirow{2}{*}{ Family history of cancer (NO) (\%) } & Positive & $4(6.3)$ & $6(9.4)$ & \multirow{2}{*}{0.644} \\
\hline & & $60(93.8)$ & $58(90.6)$ & \\
\hline \multirow{2}{*}{ Oral contraception use (NO) (\%) } & Positive & $4(6.3)$ & $10(15.6)$ & \multirow{2}{*}{0.233} \\
\hline & & $60(93.8)$ & $54(94.4)$ & \\
\hline \multirow{3}{*}{ Parity (NO) (\%) } & Multipara & $58(90.6)$ & $48(59.4)$ & \multirow{2}{*}{$0.004 *$} \\
\hline & Nulli para & $6(9.4)$ & $26(40.6)$ & \\
\hline & & $64(100)$ & $64(100)$ & \\
\hline \multirow{2}{*}{ Coital bleeding (NO) (\%) } & & $52(81.3)$ & $54(84.4)$ & \multirow{2}{*}{0.724} \\
\hline & Positive & $12(18.8)$ & $10(15.6)$ & \\
\hline \multirow{2}{*}{ Smoking (NO) (\%) } & & $54(84.4)$ & $42(65.6)$ & \multirow{2}{*}{0.066} \\
\hline & Passive & $10(15.6)$ & $22(34.4)$ & \\
\hline \multirow{2}{*}{ History of cervical lesion (NO) (\%) } & Negative & $52(81.3)$ & $42(65.6)$ & \multirow{2}{*}{0.161} \\
\hline & Positive & $12(18.8)$ & $22(34.4)$ & \\
\hline
\end{tabular}

Table 2: Clinical characteristics of the study

\begin{tabular}{|c|c|c|c|}
\hline Cervical cancer & SLE N=64 & Control N=64 & P value \\
\hline Positive & $10(15.6)$ & $0(0)$ & \multirow{2}{*}{ 0.034* } \\
\hline Negative & $54(84.4)$ & $64(100)$ & \\
\hline ASCU & $4(6.3)$ & -- & \\
\cline { 1 - 3 } CIN I & $2(3.15)$ & -- & \\
\hline
\end{tabular}




\begin{tabular}{|c|c|c|}
\hline CIN II & $2(3.15)$ & -- \\
\hline CIN III & $2(3.15)$ & -- \\
\hline
\end{tabular}

Table 3: Association between dysplastic changes of cervix by histopathology and SLE

\begin{tabular}{|c|c|c|c|c|c|c|c|c|}
\hline \multicolumn{8}{|c|}{ Histopathological result } & \multirow[b]{2}{*}{$P$ value } \\
\hline & & & normal & ASCUS & CIN 1 & CIN II & $\begin{array}{c}\text { CIN } \\
\text { III }\end{array}$ & \\
\hline \multicolumn{3}{|c|}{$\begin{array}{c}\text { Age of marriage } \\
\text { mean } \pm \text { SD }\end{array}$} & $\begin{array}{r}29.8 \\
\pm 5.8 \\
\end{array}$ & $\begin{array}{l}18.5 \\
\pm 0.7 \\
\end{array}$ & 32 & 34 & 30 & $0.019 *$ \\
\hline \multicolumn{3}{|c|}{$\begin{array}{c}\text { Duration of SLE } \\
\text { mean } \pm \text { SD }\end{array}$} & $\begin{array}{l}11.9 \\
\pm 3.9\end{array}$ & $\begin{array}{r}3.5 \\
\pm 0.7\end{array}$ & 12 & 13 & 10 & $0.014 *$ \\
\hline \multirow{4}{*}{ Oral contraception } & \multirow{2}{*}{-ve } & No & 52 & 4 & 2 & 2 & 2 & \multirow{4}{*}{0.151} \\
\hline & & $\%$ & 96.3 & 100 & 100 & 100 & 100 & \\
\hline & \multirow{2}{*}{+ ve } & No & 2 & $\mathbf{0}$ & $\mathbf{0}$ & $\mathbf{0}$ & $\mathbf{0}$ & \\
\hline & & $\%$ & 3.7 & $\mathbf{0}$ & $\mathbf{0}$ & $\mathbf{0}$ & $\mathbf{0}$ & \\
\hline & & & & & & & & \\
\hline \multirow{4}{*}{ Parity } & \multirow{2}{*}{ Multi } & No & 48 & 4 & 2 & 2 & 2 & \multirow{4}{*}{0.483} \\
\hline & & $\%$ & 88.9 & 100 & 100 & 100 & 100 & \\
\hline & \multirow{2}{*}{ Nulli } & No & 6 & $\mathbf{0}$ & $\mathbf{0}$ & $\mathbf{0}$ & $\mathbf{0}$ & \\
\hline & & $\%$ & 11.1 & $\mathbf{0}$ & $\mathbf{0}$ & $\mathbf{0}$ & $\mathbf{0}$ & \\
\hline \multirow{5}{*}{ Coital bleeding } & \multirow{3}{*}{-ve } & & & & & & & \multirow{5}{*}{$0.003 *$} \\
\hline & & No & $\mathbf{5 0}$ & $\mathbf{0}$ & $\mathbf{0}$ & $\mathbf{0}$ & $\mathbf{0}$ & \\
\hline & & $\%$ & 92.6 & $\mathbf{0}$ & $\mathbf{0}$ & $\mathbf{0}$ & $\mathbf{0}$ & \\
\hline & \multirow{2}{*}{$+v e$} & No & 4 & 4 & 2 & 2 & 2 & \\
\hline & & $\%$ & 7.4 & 100 & 100 & 100 & 100 & \\
\hline & & & & & & & & \\
\hline \multirow{4}{*}{ Marriage } & \multirow{2}{*}{ Once } & No & 48 & 4 & 2 & 2 & 2 & \multirow{4}{*}{0.521} \\
\hline & & $\%$ & 88.9 & 100 & 100 & 100 & 100 & \\
\hline & \multirow{2}{*}{ Twice } & No & 6 & $\mathbf{0}$ & $\mathbf{0}$ & $\mathbf{0}$ & $\mathbf{0}$ & \\
\hline & & $\%$ & 11.1 & $\mathbf{0}$ & $\mathbf{0}$ & $\mathbf{0}$ & $\mathbf{0}$ & \\
\hline \multirow{4}{*}{ Smoking } & \multirow[b]{2}{*}{ Negative } & No & 52 & 0 & 2 & 0 & 2 & \multirow{4}{*}{$0.0001 * *$} \\
\hline & & $\frac{1 \mathrm{NO}}{\%}$ & $\frac{52}{96.3}$ & 0 & $\frac{2}{100}$ & 0 & 100 & \\
\hline & \multirow{2}{*}{ Passive } & No & 2 & 4 & $\mathbf{0}$ & 2 & $\mathbf{0}$ & \\
\hline & & $\%$ & 3.7 & 100 & $\mathbf{0}$ & 100 & $\mathbf{0}$ & \\
\hline \multirow{4}{*}{$\begin{array}{l}\text { Family history of } \\
\text { cancer }\end{array}$} & \multirow[b]{2}{*}{-ve } & No & 50 & 4 & 2 & 2 & 2 & \multirow{4}{*}{0.573} \\
\hline & & $\%$ & 92.6 & 100 & 100 & 100 & 100 & \\
\hline & & No & 4 & $\mathbf{0}$ & $\mathbf{0}$ & $\mathbf{0}$ & $\mathbf{0}$ & \\
\hline & +ve & $\%$ & 7.4 & $\mathbf{0}$ & $\mathbf{0}$ & $\mathbf{0}$ & $\mathbf{0}$ & \\
\hline & & No & $\mathbf{5 0}$ & $\mathbf{0}$ & $\mathbf{0}$ & $\mathbf{0}$ & $\mathbf{0}$ & \\
\hline History of cervical & -ve & $\%$ & 92.6 & $\mathbf{0}$ & $\mathbf{0}$ & $\mathbf{0}$ & $\mathbf{0}$ & $0003 *$ \\
\hline lesion & & No & 4 & 4 & 2 & 2 & 2 & $0.003^{\infty}$ \\
\hline & +ve & $\%$ & 7.4 & 100 & 100 & 100 & 100 & \\
\hline & $A S C$ & typica & $\begin{array}{r}* \mathbf{p}<0.05 \\
<0.0001 \text { is } \\
\text { luamous } \\
\text { IN I cerv } \\
\text { IN II cerv } \\
N \text { III cerv }\end{array}$ & $\begin{array}{l}\text { nificant } \\
\text { ly signific } \\
\text { l undeter } \\
\text { terepithel } \\
\text { terepithel } \\
\text { terepithel }\end{array}$ & $\begin{array}{l}\text { signific } \\
\text { sion I } \\
\text { sion II } \\
\text { sion III }\end{array}$ & & & \\
\hline
\end{tabular}

Table 4: Association between premalignant changes of cervix and clinical characteristics of SLE patients 


\begin{tabular}{|c|c|c|c|c|c|}
\hline Histopathology & $\begin{array}{l}\text { Normal (-ve) } \\
54(84.4)\end{array}$ & $\begin{array}{c}\text { ASCUS } \\
4(6.3)\end{array}$ & $\begin{array}{l}\text { CIN1 } \\
2(3.1)\end{array}$ & $\begin{array}{c}\text { CIN } 11 \\
2(3.1)\end{array}$ & $\begin{array}{c}\text { CIN } 111 \\
2(3.1)\end{array}$ \\
\hline \multirow[b]{2}{*}{ Colposcopy } & $\begin{array}{l}\text { Negative } \\
56(87.5)\end{array}$ & \multicolumn{4}{|c|}{$\begin{array}{l}\text { True +ve }(n=4) \\
\text { False +ve }(n=0)\end{array}$} \\
\hline & $\begin{array}{c}\text { True -ve } \\
54(84.4) \\
\text { False -ve } \\
2(3.1)\end{array}$ & $4(6.3)$ & -- & $2(3.1)$ & $1(3.1)$ \\
\hline \multirow[b]{2}{*}{ pap smear } & $\begin{array}{l}\text { Negative } \\
58(90.6)\end{array}$ & \multicolumn{4}{|c|}{$\begin{array}{l}\text { True +ve }(n=6) \\
\text { False +ve }(n=0)\end{array}$} \\
\hline & $\begin{array}{c}\text { True -ve } \\
54(84.4) \\
\text { False - ve } \\
4(6.3)\end{array}$ & $2(3.1)$ & -- & $2(3.1)$ & $2(3.1)$ \\
\hline
\end{tabular}

Table 5: Association between histopathology, Pap smear and colposcopy

\begin{tabular}{|c|c|c|}
\hline Performance values & pap smear & Colposcopy \\
\hline Sensitivity & $60 \%$ & $80 \%$ \\
\hline Specificity & $100 \%$ & $100 \%$ \\
\hline Positive predictive value & $100 \%$ & $100 \%$ \\
\hline Negative predictive value & $93.1 \%$ & $96.4 \%$ \\
\hline
\end{tabular}

Table 6: Performance values of Pap smear and colposcopy in comparison with histopathology results

Discussion:

Cervical cancer is the second most commonly occurring cancer in women and accounts for up to 300000 annual deaths [12]. Overall, the 5-year survival rate has been reported to be $73 \%$, but the prognosis unsatisfactory [13].

The causes of cervical cancer in various sources includes early sexual activity, multiple sexual partners, HPV infection, genital warts, sexually transmitted diseases, genital tract abnormalities, age, smoking, passive smoke, poor nutrition, immunodeficiency and malnutrition. [14].
Several studies have shown a possible link between SLE and cervical cancer. Along with a high infection rate of HPV in SLE patients, many studies have shown an increased incidence of cervical cancer in SLE patients. Moreover, other studies have noted a high risk of abnormal Pap tests in women with SLE [15].

SLE is a multi-organ system, autoimmune disease with numerous immunological and clinical manifestations. It is believed to develop as a result of dysregulation of the immune system, ultimately leading to the clinical features of inflammation [15]. Also, it was reported an association between immunological disorder and cervical premalignant and malignant abnormalities [16, 17]. 
In addition to the clinical manifestations of SLE itself, female patients also have to contend with a heightened risk of developing abnormal cervical smears and squamous intra-epithelial lesions of the cervix as well as other cancers [18].

Interesting researches have shown that SLE syndrome represents a permissive effect of immunosuppression on increased host susceptibility to high cancer-risk and infections, the causative agents of CIN and cervical cancer [19].

Our study was conducted to determine the prevalence of abnormal cervical smear and colposcopic finding in patients with SLE. Ourcase control study was designed on64 SLE female patients as well as 64 females healthy volunteers were selected as control group.

In this study, there is a significant association between cervical cancer and SLE patients $(\mathrm{p}=0.034) .4$ patients $(6.3 \%)$ of SLE had ASCUS while 2patients $(3.1 \%)$ of SLE had CIN I type as well as 2 patients $(3.1 \%)$ of SLE had CIN II, 2 patients (3.1\%) of SLE had CIN III .

We confirm recent results by Cao and his colleagues in 2015 who detected high significant association of cervical cancer and SLE patients and reported that cervical cancer was one of common cancers between SLE patients [18].

We also in harmony with earlier worldwide results of They had demonstrated cervical neoplasia among common cancers on top of SLE disease [20].

Moreover, we agree with a large meta-analysis research by Liu and hiscoworkers applied on 2011, there was a large difference between case and control groups with an increased risk of cervical neoplasia with SLE. The consensus in the literature suggests that immunosuppressive treatment probably does contribute to the development of cervical disease in patients with SLE as well as the effect of the disease itself [21]. Interestingly, we share recent Egyptian research results of $\mathrm{Al}$ - who detected and studied the prevalence of abnormal cervical smears in SLE patients, they conducted that cervical smear is easy, safe and noninvasive technique for screening and early detection of cervical neoplasia in SLE patients. Among these 4 positive patients, 3 were having ASCUS and one was having LSIL while negative results were detected in control group [7].

We also agree with previous study, they reported that SLE itself was identified as independent risk factors for high risk HPV infection among Korean women along with $\geq 2$ sexual partners. High-risk HPV infection and cervical cytological abnormalities were more common among Korean women with SLE than controls. They concluded that SLE itself can be a risk factor for HPV infection among Korean women, suggesting the importance of close monitoring of cervical cytology in SLE [22]. Also, they detected epithelial dysplasia in 8 patients, atypical squamous cells of undetermined significance (ASCUS) in 7 patients, and carcinoma in situ (CIN) in 7 patients.

We also agree with the most recent study in April 2017 by they Based on 121 events of cervical neoplasia during 23136 person-years among SLE patients, there was an increased risk of any cervical neoplasia compared with the general population, but not invasive cervical cancer [23]. The subcohort treated with other immunosuppressants was at highest risk of cervical neoplasia.
Although we could not evaluate the immunosuppressive treatment role in cervical cancer incidence due to short time of study and lake of follow up period, however we found a disagreement among different studies regarding the role of immunosuppressive drugs as a predisposing factor for these cervical abnormalities. On one side, most of the studies showed no association between the use of immunosuppressive agents and increased frequency of cervical abnormalities, while two others have suggested the participation of intravenous cyclophosphamideon the development of this cervical complication. [24]

In our study, when we studied clinical characteristics and type of cervical cancer, there is a significant association between ASCUS with younger age of marriage $(\mathrm{p}=0.019)$ and shorter duration of SLE $(\mathrm{p}=0.014)$. While, other studied parameters did not show any significant association.

We are in disharmony with a study could not detect any significant association between duration of SLE and cancer development although they had long period of follow up [25].

We did not detect a significant association between any type of cervical cancer and oral contraception use in SLE patients. Which disagree with who reported oral contraceptive pills as a possible risk factor in cervical cancer. This conflict can be due to different in number of study participants and higher number of cervical cancers SLE patients in the later study [26].

In this study, there is a high significant association between cervical cancer (especially ASCUS and CIN II) with passive smoking. This result was not coenside with earlier research on malignancy on top of SLE; who highlighted smoking as high-risk factor in lung cancer rather than cervical cancer [27].

We also in disagreement with who detected smoking in a similar ratio between SLE patients and control group with no significant difference [28].

Previous studies have demonstrated an increased prevalence of atypical cervical smears in patients with SLE even in asymptomatic patients, ranging from 24 to $36 \%$, compared with a prevalence of $\leq 5-15 \%$ in controls [29].

Pap smear abnormalities in female patients with autoimmune diseases had been previously investigated. Pap smear screening was done for autoimmune group include SLE, Rheumatoid arthritis, ankylosing arthritis and systemic sclerosis compared with normal counterparts [17].

The two groups were matched for demographics and known risk factors of cervical malignancy. Frequency of abnormal Pap smear testing was significantly higher in the case group comparing with that in the controls. Frequency of abnormal Pap smear testing was higher in the patients with SLE and RA comparing with that in the controls [17].

In our study, we investigated the Performance values of Pap smear and colposcopy in comparison with histopathology results, pap smear had $60 \%$ sensitivity, $100 \%$ specificity, $100 \%$ positive predictive value, $93.1 \%$ negative predictive value. While colposcopy showed higher results $80 \%$ sensitivity, $100 \%$ specificity, $100 \%$ positive predictive value, $96.4 \%$ negative predictive value. 
This come with accordance with the result of who detected sensitivity in $60 \%$ of pap smear, $87 \%$ specificity, $43 \%$ positive predictive value, $93 \%$ negative predictive value with higher values regarding colposcopy. It had 75\% sensitivity, 99\% specificity, 94\% positive predictive value, 96\% negative predictive value [30].

Determining accurate cancer risk in a disease like SLE, which nowadays may affect patients for several decades, is very challenging. While, mortality and morbidity were higher in SLE patients as well as high incidence of cancer elevated with long standing SLE, regular screening investigation must be applied for all SLE patients especially who had possible risk factors. Colposcopy show higher specificity and sensitivity

\section{Conclusion}

- There is a significant association between cervical cancer and SLE patients

- There is a significant association between ASCUS with younger age of marriage

- There is a significant association between ASCUS with shorter duration of SLE .

- There is a significant association between cervical cancer with coital bleeding, previous history of cervical lesion and passive smoking.

- Performance values of Pap smear in comparison with histopathology results, Pap smear had 60\% sensitivity, 100\% specificity, $100 \%$ positive predictive value, $93.1 \%$ negative predictive value.

Recommendations

Patients with SLE had higher risk for cervical dysplasia than general population. Thus, gynecological visits at shorter intervals (3-6months) recommended for these patients especially those with previous history of younger age of marriage, cervical lesion, with coital bleeding and with passive smoking.

\section{Limitation:}

- $\quad$ Long time follow up is recommended to detect the relation between long standing SLE and cervical abnormalities

- Long time follow up for immunosuppressive treatment is also recommended to detect any role of immunosuppressive therapy in induction of cervical cancer.

- $\quad$ extended study is recommended to be applied in large number of SLE patients to detect various type of cervical changes

- $\quad$ variable degree of SLE activity should be enrolled in the study to evaluate the relation between SLE disease activity and type of cervical cancer.

\section{References}

1. Gakidou E, Nordhagen S, Obermeyer Z. (2008) Coverage of cervical cancer

screening in 57 countries: low average levels and large inequalities. PLoS Med; 5(6): e132.

2. Howley PM and Lowy DR. (2012) Papillomaviruses and their replication. In Knipe DM and Howley PM (editors), Fields Virology. 4th edn; 2197-2229.

3. Ault A. (2006) Epidemiology and natural history of human papillomavirus infections in the female genital tract. J. Infect. Dis. Obstet. Gynecol; 40470.

4. Ishida WS, Singto Y, Kanjanavirojkul N et al. (2004) Co-risk factors for HPV infection in northeastern Thai women with cervical carcinoma. Asian Pac J Cancer Prev 5: 383-386.

5. Jones, M.H.; Jerkins, D. and Singer, A. (2006) Regular audit of colposcopic biopsies in women with a mildly dyskaryotic or borderline cervical smear results in fewer cases of CIN III. Cytopathology, 7(1):17-24.

6. Kriiger Kjaer S, Chackerian B, van den Brule AJC, et al. (2010) High-risk human papillomavirus is sexually transmitted: evidence from a follow up study of virgins starting sexual activity (intercourse). Cancer Epidemiol. Biomarkers Prev; 10: 101-106.

7. Al-Sherbeni H, Fahmy A, and Sherif N. (2015) Predisposition to Cervical Atypia in Systemic Lupus Erythematosus: A Clinical and Cytopathological Study. Autoimmune Diseases, 751853

8. ACOG Practice Bulletin (2013) clinical management guidelines for obstetrician-gynecologists. Number 45, August 2003. Cervical cytology screening (replaces committee opinion 152, March 1995 Obstet Gynecol; 102(2): 417-427.

9. Harris RWC, Brinton LA, Cowdell RH, et al. (1980) Characteristics of women with dfysplasia or carcinoma in situ of the cervix uteri. Br J Cancer; 42: 359-369.

10. Baron RM and Kenny DA. (1986) The moderator-mediator variable distinction in social psychological research: conceptual, strategic, and statistical considerations. J Pers Coc Psychol. 51(6):1173-1182.

11. Dean F. (2006) statistical methods in scientific researches. Europian Journal of Scientific Research. 14 (3).

12. Cantor SB, Atkinson EN, Cardenas-Turanzas M, Benedet JL, Follen M, MacAulay C. (2005) Natural history of cervical intraepithelial neoplasia: a meta-analysis. Acta Cytol 49:405415

13. Jones, M.H.; Jerkins, D. and Singer, A. (2006) Regular audit of colposcopic biopsies in women with a mildly dyskaryotic or borderline cervical smear results in fewer cases of CIN III. Cytopathology, 7(1):17-24.

14. Ishida WS, Singto Y, Kanjanavirojkul N et al. (2004) Co-risk factors for HPV infection in northeastern Thai women with cervical carcinoma. Asian Pac J Cancer Prev 5: 383-6.

15. Ben-Menachem E (2010) Systemic lupus erythematosus: a review for anesthesiologists. Anesth Analg;111:665-676.

16. Dobkin PL, Da Costa D, Fortin PR et al. (2001) Living with lupus: a prospective pan-Canadian study. J Rheumatol, 28: 2442-2448

17. Esmaeili $\mathrm{H}$ and ghahremanzadeh K. (2011) association of pap smear abnormalities with autoimmune disorder. Pak j boil sci 15;14 (10):600-614. analysis. Acta Cytol, 49:405-415. 
18. Cao L, Tong H, Xu G. (2015) Systemic Lupus Erythematous and Malignancy Risk: A Meta-Analysis. PLoS One. 10(4): $\mathrm{e} 0122964$.

19. Bao YP, Li N, Smith JS, Qiao YL. (2008) Human papillomavirus type distribution in women from Asia: a metaanalysis. Int J Gynecol Cancer 18:71-79.

20. Bernatsky S, Clarke A, Labreque J et al. (2012) Lymphoma risk in systemic lupus: effects of disease activity versus treatment. Arthritis Rheum; 63(10S):

21. Liu H, Ding Q, Yang K, et al. (2011) Meta-analysis of systemic lupus erythematosus and the risk of cervical neoplasia. Rheumatology; 50(2): 343-348.

22. Lee Y, Choe C, Park C, Park Y, Lee S. (2010) Prevalence of Human Papilloma Virus Infections and Cervical Cytological Abnormalities among Korean Women with Systemic Lupus Erythematosus. J Korean Med Sci 25: 1431-1437

23. Wadström H, Elizabeth V. Sjöwall C, Askling J, Simard F. (2017) Cervical neoplasia in systemic lupus erythematosus: a nationwide study. Rheumatology (Oxford), 56 (4): 613-619.

24. Nath R, Mant C, Luxton J et al. (2007) High risk of human papillomavirus type 16 infections and of development of cervical squamous intraepithelial lesions in systemic lupus erythematosus patients. Arthritis Rheum, 57: 619-625.

25. Dresang LT (2013) Cervical cancer with a normal Pap. WMJ; 102: 4.
S25791.

26. Bernatsky S, Boivin JF, Joseph L et al. (2008) The relationship between cancer and medication exposures in systemic lupus erythematosus: a case-cohort study. Ann. Rheum. 67: 74-79.

27. Kale M, Ramsey-Goldman R, Gordon C, Ann E. (2010) Malignancies in systemic lupus erythematosus. Autoimmun Rev. 9(4): 10.

28. Dey D, Kenu E, and Isenberg DA. (2013) Cancer complicating systemic lupus erythematosus - a dichotomy emerging from a nested case-control study. Lupus. 22(9): 919-927.

29. Dhar JP, Kmak D, Bhan R, Pishorodi L, Ager J, Sokol RJ. (2001) Abnormal cervicovaginal cytology in women with lupus: a retrospective cohort study. Gynecol Oncol. 82:4-6.

30. Girbash E F, Atta DS, Fahmy DS, Abdelwahab M. (2016) Abnormal Pap Tests In Systemic Lupus Erythematosis: A Cytopathological And Human Papillomavirus Testing Study. International Journal of Advanced Research 4 (5): 1707-1715

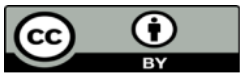

This work is licensed under Creative Commons Attribution 4.0 License

To Submit Your Article Click Here: Submit Article

DOI:10.31579/2642-9756/017
Ready to submit your research? Choose Auctores and benefit from:

* fast, convenient online submission

* rigorous peer review by experienced research in your field

* rapid publication on acceptance

* authors retain copyrights

* unique DOI for all articles

* immediate, unrestricted online access

At Auctores, research is always in progress.

Learn more https://www.auctoresonline.org/journals/women-

health-care-and-issues 
